\title{
SOFT SENSOR DO PROCESSO GRATE KILN DA PELOTIZAÇÃO DA VSB*
}

Davi Silva Braga ${ }^{1}$

Lucas Gabriel Rabelo Criscuolo²

Felipe Barbosa Reis ${ }^{3}$

Tamires Miranda Milagres Portilho 4 Ronaldo Santos Sampaio ${ }^{5}$

\section{Resumo}

Controlar o perfil térmico dos fornos de uma planta de pelotização é essencial para se garantir a qualidade das pelotas e manter a competitividade da produção. A medição online de variáveis-chave é restrita devido às condições da planta ou limitações tecnológicas, fazendo-se necessário a utilização de um modelo matemático (Soft Sensor) para estimar essas variáveis e, então, exercer maior controle sobre a qualidade e custos do processo. Através de balanços térmico e mássico, o modelo é capaz de predizer o perfil térmico das pelotas e as perdas, térmicas e mássicas, além de simular mudanças no processo e implicações no consumo de combustível. Com o modelo, observou-se a possibilidade de redução de $5 \%$ de perda térmica, resultando em redução de $2 \%$ do consumo de combustível, devido à melhora da recuperação de calor da zona 2 do resfriador para a pré-queima 1 do forno grelha. O trabalho foi realizado na planta da Vallourec \& Sumitomo Tubos do Brasil (VSB).

Palavras-chave: Pelotização; Soft Sensor; Grate Kiln; Modelagem.

\section{Abstract}

\section{SOFT SENSOR FOR THE VSB GRATE KILN}

Controlling the thermal profile of the furnaces of a pelletizing plant is essential to ensure the quality of pellets and keep the competitiveness of production. Online measurement of KPls is restricted due to the plant conditions or technological limitations, making it necessary to use Soft Sensor for estimating these variables and then exert greater control over the quality and cost of the process. By heat and mass balances, the model is able to predict the thermal profile of pellets and the mass loss, and simulate process changes and implications for heat loss and fuel consumption. With the model, the possibility of reduction of $5 \%$ heat loss resulting in reduction of $2 \%$ of fuel consumption was observed due to the improvement in heat recovery from cooler zone 2 into pre-firing 1 at travelling grate furnace. The study was conducted at Vallourec \& Sumitomo Tubos do Brasil (VSB).

Keywords: Pelletizing plant; Soft Sensor; Grate Kiln; Modeling.

1 Bacharel em Engenharia Química - UFMG, Engenheiro de Processos, Pelotização, Vallourec \& Sumitomo Tubos do Brasil, Jeceaba, Minas Gerais, Brasil.

2 Bacharel em Engenharia de Controle e Automação - UFMG, Engenheiro de Processos, Pelotização, Vallourec \& Sumitomo Tubos do Brasil, Jeceaba, Minas Gerais, Brasil.

3 Graduando em Engenharia Mecânica - UFMG, Estagiário de Processo, Vallourec Tubos do Brasil S.A, Belo Horizonte, Minas Gerais, Brasil.

4 Graduando em Engenharia Metalúrgica - IFGM, Estagiária de Processo, Pelotização, Vallourec \& Sumitomo Tubos do Brasil, Jeceaba, Minas Gerais, Brasil.

5 Ph.D. em Engenharia Metalúrgica - Carnegie Mellon University, Consultor, Vallourec Tubos do Brasil S.A, Belo Horizonte, Minas Gerais, Brasil. 


\section{INTRODUÇÃO}

Pelotização é um processo de aglomeração de ultrafinos de minérios de ferro (fração menor que $0,150 \mathrm{~mm}$ ), juntamente com quantidades pré-definidas de aglomerantes, calcários e finos de combustível, a fim de se obter um produto semi-acabado de alto valor em uso para altos fornos; a pelota de minério de ferro.

A pelota é um aglomerado esférico com composição química pré-definida e granulometria entre 8 a $16 \mathrm{~mm}$, obtido por rolamento em tambores ou discos rotativos. Como as pelotas verdes possuem baixa resistência mecânica, é necessário submetê-las a um tratamento térmico de endurecimento, aquecendo-as até $1350^{\circ} \mathrm{C}$. Durante o endurecimento ocorre o crescimento e a recristalização dos grãos, reações entre a ganga dos minérios e adições, chamada de fase líquida, aumentando-se então a resistência mecânica. Após tratamento térmico, as pelotas são usualmente chamadas de pelotas queimadas, segue Figura $1 \mathrm{com}$ pelotas produzidas na pelotização da Vallourec \& Sumitomo Tubos do Brasil (VSB).

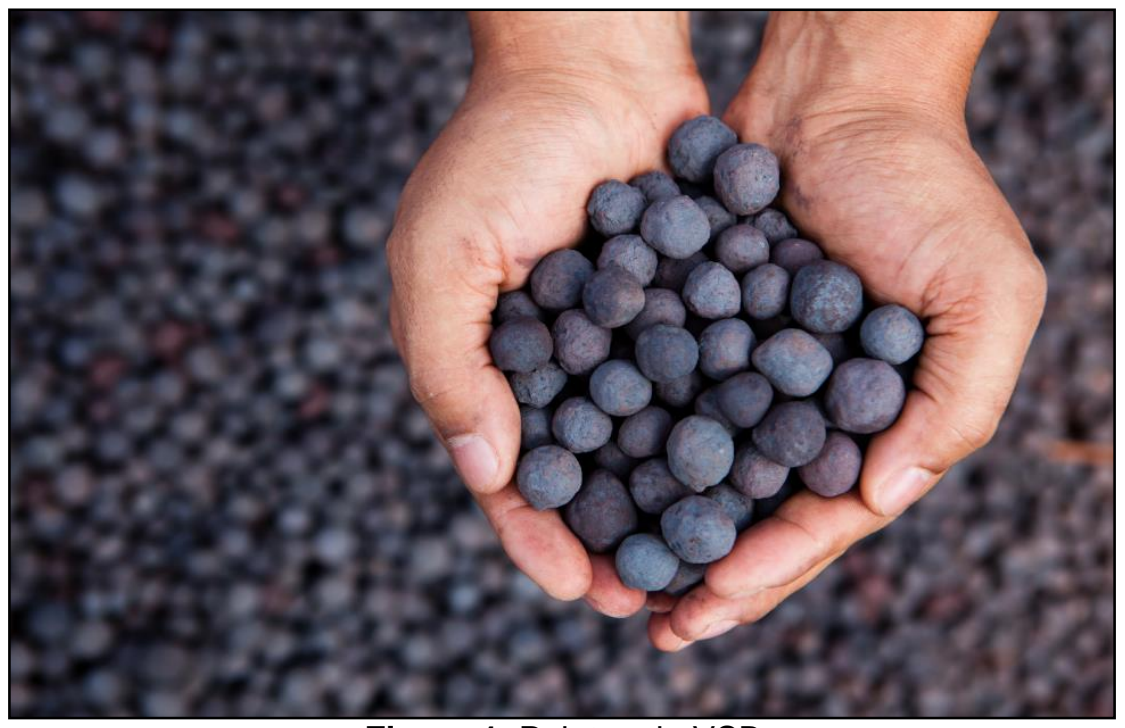

Figura 1. Pelotas da VSB

Tradicionalmente três tipos de fornos de tratamento térmico são empregados em pelotização: Forno Cuba (Shaft), Forno Grelha Reto (Travelling Grate) e Grate-Kiln (Grelha e Forno Rotativo, inspirado no processo de fabricação de cimento Lepol).

O sistema Grate Kiln, responsável pela queima e endurecimento das pelotas na pelotização da VSB, possui três etapas sequenciais de processamento: forno grelha forno rotativo e resfriador circular, conforme se pode observar na Figura 2 abaixo.



Figura 2. Modelo esquemático da planta de pelotização da VSB 
O forno grelha é composto por três zonas. A primeira delas, a secagem, é responsável pela retirada da água contida nas pelotas verdes através da evaporação a $100^{\circ} \mathrm{C}$. A água de cristalização de sais e combinações de hidratos só se desprende a altas temperaturas. A velocidade de secagem deve ser adequada para evitar um enfraquecimento da estrutura da pelota devido a rachaduras ou fragmentações. Em seguida, têm-se a pré-queima 1 e a pré-queima 2, que possui queimadores auxiliares a fim de aumentar o aporte térmico dessas zonas. Elas são responsáveis pela retirada da água de cristalização, combustão do carbono e calcinação dos carbonatos presentes nos calcários. Já o forno rotativo é o principal fornecedor de energia do sistema. Ele promove o tratamento térmico das pelotas com a utilização de queimador axial de alta potência, alimentado a gás natural e/ou carvão pulverizado, garantindo resistência mecânica às pelotas. Em relação aos outros fornos comumente utilizados, a queima em fornos rotativos é mais homogênea, por promover troca térmica pelos mecanismos de condução por contato com o refratário aquecido, convecção com ar quente e radiação direta da chama. As pelotas produzidas possuem melhores índices de abrasão devido ao processo de tamboreamento provocado pela rotação do forno. O forno rotativo promove dois mecanismos para conferir resistência à compressão às pelotas, recristalização dos grãos e formação da escória, fase líquida no espaço intergranular. O resfriador circular, constituído por três zonas, tem como objetivo retirar o máximo de calor das pelotas, o reaproveitado em diferentes áreas da planta.

Como se pode observar, o sistema Grate Kiln, em estudo, possui pontos de reaproveitamento energético. A secagem utiliza ar a uma temperatura aproximada de $250^{\circ} \mathrm{C}$, vindo da pré-queima 2 , que por sua vez recebe o calor do gás de combustão do forno rotativo, cujo valor se encontra em torno de $1000^{\circ} \mathrm{C}$. A préqueima 1 recebe o ar utilizado para arrefecer as pelotas na zona 2 do resfriador, que é transportado através de uma tubulação revestida com isolamento térmico. O forno rotativo recebe ar a aproximados $950^{\circ} \mathrm{C}$, que foi aquecido durante a troca térmica para arrefecer as pelotas na zona 1 do resfriador. Já na zona 3, todo ar é perdido para o meio ambiente, após trocar calor com as pelotas, pois normalmente está abaixo da temperatura de $100^{\circ} \mathrm{C}$.

O presente trabalho apresenta uma proposta de modelo matemático para a pelotização, visto que medições frequentes de algumas variáveis se tornam impraticáveis devido a limitações da planta e limitações de tecnologias disponíveis. O modelo tem uma vasta aplicabilidade, podendo predizer o perfil térmico das pelotas, bem como sua perda mássica, além de simular eventuais mudanças no processo e suas implicações nas perdas térmicas e no consumo de combustível.

\section{MATERIAIS E MÉTODOS}

O modelo térmico da Pelotização da VSB foi desenvolvido para estimar as perdas térmicas e de massas em todas as etapas do processo Grate Kiln. Para isso, utilizou-se balanços de massa e de energia, além da composição e quantidade dos insumos e combustíveis utilizados na planta. A interface do modelo está esquematizada na Figura 3. 
$46^{\circ}$ Redução

$17^{\circ}$ Minério de Ferro

$4^{\circ}$ Aglomeração

ISSN 2176-3135

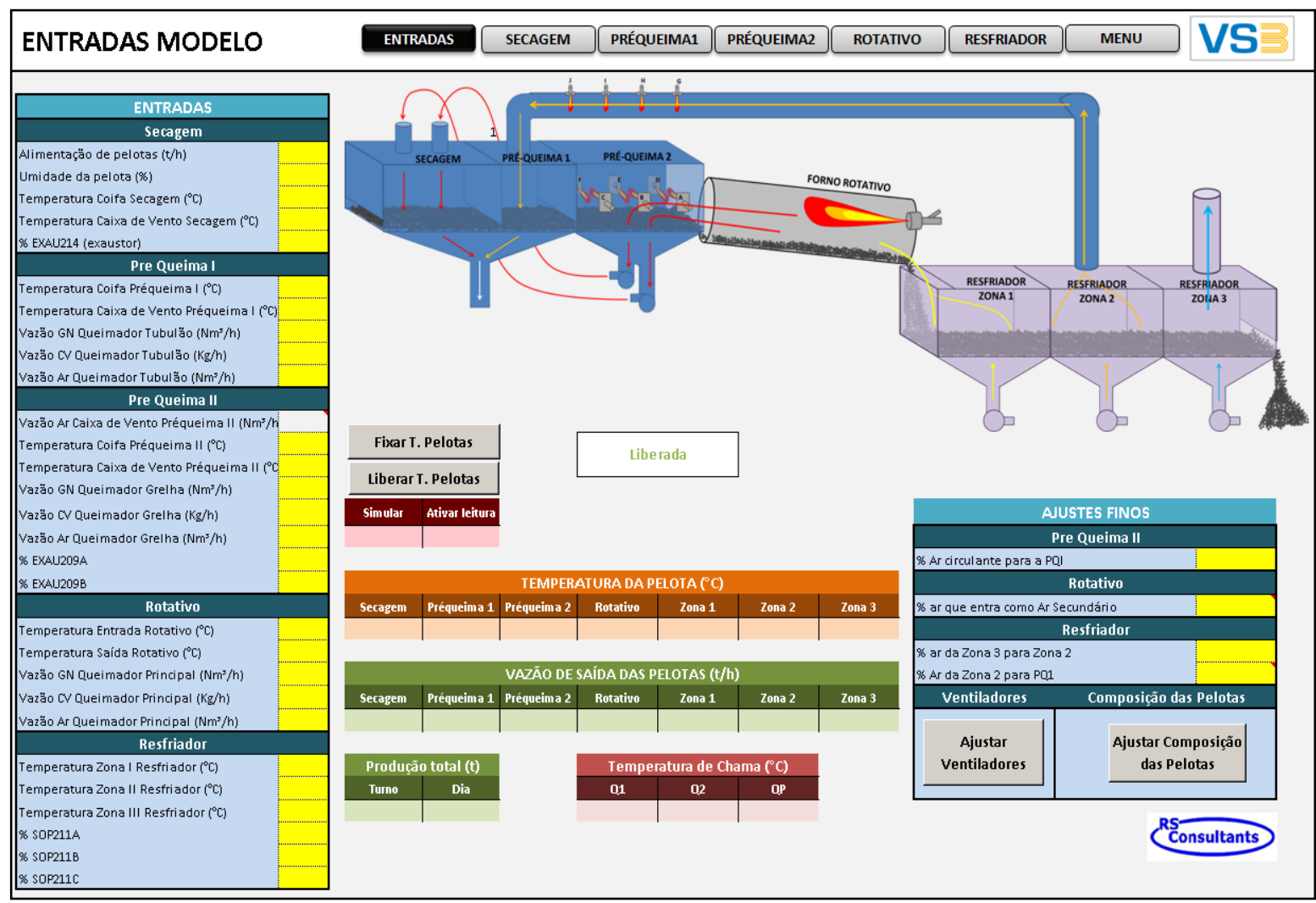

Figura 3. Interface do Soft Sensor da pelotização da VSB

\subsection{Balanço de massa}

O balanço de massa é de inteira importância para o modelo, pois é através dele que definimos as quantidades energéticas que são transportadas por unidade de massa que entra e sai do sistema.

A composição química de cada matéria-prima, de cada insumo, ou seja, de cada entrada, influencia diretamente no balanço de energia do processo de pelotização, pois a sua maior ou menor concentração significa uma maior ou menor energia liberada ou absorvida quando a temperatura de ativação da reação é atingida.

\subsubsection{Composição da pelota verde}

Como primeiro dado de entrada, tem-se a composição da pelota verde, que pode ser vista na Tabela 1. Estes parâmetros foram considerados como valores de entrada, podendo ser editados e calculados novamente. Para se calcular essa composição de pelota foi considerada a composição e dosagem dos insumos, calcários, combustível sólido e aglomerante praticados pela VSB.

Tabela 1. Composição da pelota verde

\begin{tabular}{ccccccc}
$\mathrm{Fe}_{2} \mathrm{O}_{3}(\%)$ & $\mathrm{FeO}(\%)$ & $\mathrm{FeO} \cdot \mathrm{OH}(\%)$ & $\mathrm{Fe}(\mathrm{OH})_{2}(\%)$ & $\mathrm{SiO}_{2}(\%)$ & $\mathrm{Al}_{2} \mathrm{O}_{3}(\%)$ & $\mathrm{CaO}(\%)$ \\
\hline 64,4 & 0,9 & 14,7 & 0,0 & 3,8 & 0,6 & 0,2 \\
\hline $\mathrm{CaCO}_{3}(\%)$ & $\mathrm{MgO}(\%)$ & $\mathrm{MgCO}_{3}(\%)$ & $\mathrm{MnO}(\%)$ & $\mathrm{P}_{2} \mathrm{O}_{5}(\%)$ & $\mathrm{C}(\%)$ & $\mathrm{H}_{2} \mathrm{O}(\%)$ \\
\hline 3,4 & 0,1 & 0,9 & 0,1 & 0,1 & 0,6 & 10,0 \\
\hline
\end{tabular}




\subsubsection{Reações químicas}

A pelota verde possui cerca de $10 \%$ de umidade, que é retirada na zona de secagem do forno grelha. Este processo é representado pela reação seguinte:

$$
\mathrm{H}_{2} \mathrm{O}(\mathrm{I})+\text { calor } \rightarrow \mathrm{H}_{2} \mathrm{O}(\mathrm{g})(2.1)
$$

É necessário que a pelota atinja a temperatura mínima de $100^{\circ} \mathrm{C}$ para que haja evaporação total da água. $O$ aporte térmico desta zona é proveniente da recuperação de calor da pré-queima 2. $\mathrm{O}$ ar quente passa por um processo de despoeiramento e é utilizado para aquecer a zona de secagem.

A pelota sem umidade é direcionada para a pré-queima 1.0 ar quente, recuperado da zona 2 do resfriador circular é utilizado para aquecer as pelotas. Nesta etapa do processo a água de cristalização dos sais e combinações de hidratos se desprende conforme reações abaixo:

$$
\begin{array}{r}
2 \mathrm{FeO} \cdot \mathrm{OH}+\text { calor } \rightarrow \mathrm{Fe}_{2} \mathrm{O}_{3}+\mathrm{H}_{2} \mathrm{O}(2.2) \\
2 \mathrm{Fe}(\mathrm{OH})_{2}+1 / 2 \mathrm{O}_{2} \rightarrow \mathrm{Fe}_{2} \mathrm{O}_{3}+2 \mathrm{H}_{2} \mathrm{O}(2.3) \\
\mathrm{Al}_{2} \mathrm{O}_{3} \cdot 3 \mathrm{H}_{2} \mathrm{O}+\text { calor } \rightarrow \mathrm{Al}_{2} \mathrm{O}_{3}+3 \mathrm{H}_{2} \mathrm{O}(2.4) \\
\mathrm{Ca}\left(\mathrm{H}_{2} \mathrm{O}\right)+\text { calor } \rightarrow \mathrm{CaO}+\mathrm{H}_{2} \mathrm{O}(2.5)
\end{array}
$$

Nesta etapa se inicia também a combustão do combustível sólido. Conforme reação de Boudouard abaixo.

$$
\mathrm{C}+\mathrm{O}_{2} \rightarrow \mathrm{CO}_{2}+\text { calor (2.6) }
$$

Durante o aquecimento das pelotas à temperatura acima de $600^{\circ} \mathrm{C}$, inicia-se a calcinação dos carbonatos presentes nos calcários calcítico $\left(\mathrm{CaCO}_{3}\right)$ e dolomítico $\left(\mathrm{MgCO}_{3}\right)$, cuja reações segue abaixo:

$$
\begin{gathered}
\mathrm{CaCO}_{3} \rightarrow \mathrm{CaO}+\mathrm{CO}_{2}(2.7) \\
\mathrm{MgCO}_{3} \rightarrow \mathrm{MgO}+\mathrm{CO}_{2}(2.8)
\end{gathered}
$$

A liberação de $\mathrm{CO}_{2}$ pode ocasionar a geração de trincas devido à expansão volumétrica deste gás.

A compreensão e correta definição das reações químicas que ocorrem no processo de queima demandam estudo aprofundado com uso de microscopia, avaliação de termodinâmica e cinética química das reações. No presente modelo foram consideradas as definições segundo Juvilar [1].

As ligações químicas para a formação dos silicatos estão descritas abaixo.

Toda alumina $\left(\mathrm{Al}_{2} \mathrm{O}_{3}\right)$ reage com a sílica.

Todo óxido de magnésio $(\mathrm{MgO})$ reage com a sílica.

$$
\mathrm{Al}_{2} \mathrm{O}_{3}+\mathrm{SiO}_{2} \rightarrow \mathrm{Al}_{2} \mathrm{O}_{3} \cdot \mathrm{SiO}_{2}(2.9)
$$

$$
\mathrm{MgO}+\mathrm{SiO}_{2} \rightarrow \mathrm{MgO} \mathrm{SiO}_{2}(2.10)
$$

A sílica $\left(\mathrm{SiO}_{2}\right)$ restante reage com o óxido de cálcio $(\mathrm{CaO})$.

$$
\mathrm{CaO}+\mathrm{SiO}_{2} \rightarrow \mathrm{CaO} . \mathrm{SiO}_{2}
$$

Todo óxido de cálcio restante $(\mathrm{CaO})$ reage com o minério de ferro $\left(\mathrm{Fe}_{2} \mathrm{O}_{3}\right)$, formando compostos denominados ferritos de cálcio (CF).

$$
2 \mathrm{CaO}+2 \mathrm{Fe}_{2} \mathrm{O}_{3} \rightarrow 2 \mathrm{CaO} . \mathrm{Fe}_{2} \mathrm{O}_{3}(2.12)
$$


Observa-se presença de $\mathrm{FeO}$ nas pelotas queimadas, através de análise química por fluorescência de raio $X$, normalmente com valores entre 0,10 a $0,25 \%$.

Segundo Meyer [2], quando se pratica temperaturas de queima acima de $1400^{\circ} \mathrm{C}$ a reação de redução da hematita é favorecida. Essa característica pode ser verificada através de atração ferromagnética das pelotas em relação a um imã comum.

\subsubsection{Entradas de Ar}

A planta possui três ventiladores, sendo um em cada zona do resfriador circular, além de três exaustores, sendo dois deles entre a pré-queima 2 e a secagem. $O$ último destes é o exaustor principal da planta que se encontra na saída da secagem e da pré-queima 1. Todo o gás quente derivado do processo passa por um precipitador eletrostático, cuja função é retirar os particulados, preservando a vida útil do exaustor e permitindo controle das emissões dentro dos limites legais.

Outra entrada relevante de ar no sistema é a vazão de ar primário de combustão do queimador principal do forno rotativo. Outros queimadores menores também promovem entrada de ar, quando em funcionamento.

Logo, a vazão mássica de ar (em $\mathrm{kg}$ ) que entra na planta é definida a partir da velocidade de funcionamento de cada ventilador, das vazões de ar primário de combustão, assim como umidade relativa do ar.

As pressões nos compartimentos do processo são em maiorias negativas, permitindo a entrada indesejada de ar frio, denominado ar falso. Sob o leito de pelotas, observa-se pressões entre -40 e -150 Pa enquanto que nas caixas de vento esse valores estão na ordem de $-1000 \mathrm{~Pa}$. Não é possível medir apropriadamente o volume de ar falso, sendo definido no modelo através do balanço de massas entre entradas e saídas de ar do sistema.

Utilizando-se a fórmula abaixo, calcula-se, portanto, a vazão em massa do ar proveniente dos ventiladores e do ar primário da combustão.

$$
\left\{\left[\% \mathrm{O}_{2}{ }^{*} 32 \frac{\mathrm{g}}{\mathrm{mol}}+\% \mathrm{~N}_{2}{ }^{*} 28 \frac{\mathrm{g}}{\mathrm{mol}}+\% \mathrm{H}_{2} \mathrm{O}^{*} 18 \frac{\mathrm{g}}{\mathrm{mol}}\right] / 0,0224 \frac{\mathrm{mol}}{\mathrm{Nm}^{3}}\right\}^{*} \operatorname{vazão} \operatorname{ar}\left(\frac{\mathrm{Nm}^{3}}{\mathrm{~h}}\right)
$$

\subsubsection{Combustível}

O combustível utilizado para aquecimento das pelotas é o gás natural (GN). A sua vazão é variável de processo da planta e sua composição química é de importância para se definir o seu potencial energético. A Tabela 2 mostra a composição média do combustível utilizado.

Tabela 2. Composição média do GN

\begin{tabular}{llllll}
\hline $\mathbf{C H} 4(\%)$ & $\mathbf{C 2 H} 6(\%)$ & $\mathbf{C 3 H 8}(\%)$ & $\mathbf{C 4 H 1 0}(\%)$ & $\mathbf{N 2}(\%)$ & $\mathbf{C O 2}(\%)$ \\
\hline 91,17 & 5,11 & 1,49 & 0,75 & 0,56 & 0,92 \\
\hline
\end{tabular}

\subsection{Balanço térmico}

Com a medição frequente das temperaturas de entrada e saída de ar de cada zona da planta, e o balanço de massa realizado, é possível então estimar o perfil térmico das pelotas. 


\subsubsection{Calor das reações químicas}

Através da energia padrão de formação dos elementos químicos da Tabela 3, bem como as equações 2.1 a 2.14 , foi possível calcular a energia liberada ou absorvida durante o processo de tratamento térmico da pelota.

Tabela 3. Energia padrão de formação dos elementos químicos

\begin{tabular}{|c|c|c|c|}
\hline Elemento & $\mathrm{Kcal} / \mathrm{mol}$ & Elemento & $\mathrm{Kcal} / \mathrm{mol}$ \\
\hline $\mathrm{FeO}$ & $-24,271$ & $\mathrm{CaCO}_{3}$ & 42,746 \\
\hline $\mathrm{Fe}^{-}$ & $-98,15$ & $\mathrm{Ca}(\mathrm{OH})_{2}$ & 26,088 \\
\hline $\mathrm{FeO} \cdot \mathrm{OH}$ & 6,793 & $\mathrm{MgCO}_{3}$ & 24,246 \\
\hline $\mathrm{Fe}(\mathrm{OH})_{2}$ & 43,859 & $\mathrm{Mg}(\mathrm{OH})_{2}$ & $-192,65$ \\
\hline $\mathrm{Fe}(\mathrm{OH})_{3}$ & 14,959 & C & $-94,054$ \\
\hline $\mathrm{FeCO}_{3}$ & $-13,504$ & H & $-28,9$ \\
\hline $\mathrm{Al}_{2} \mathrm{O}_{3} \cdot 3 \mathrm{H}_{2} \mathrm{O}$ & 44,4 & $\mathrm{H}_{2} \mathrm{O} \mathrm{L}$ & 10,52 \\
\hline
\end{tabular}

\subsubsection{Combustão}

No queimador principal é utilizado gás natural como fonte de energia para a planta. O seu poder calorífico inferior ( $\mathrm{PCl}$ ) se encontra na faixa $9000 \mathrm{kcal} / \mathrm{Nm}^{3}$, e é calculado de acordo com a sua composição química, já explicitada na Tabela 2.

A combustão do GN libera calor que é transferido para as pelotas, principalmente, pela radiação da chama. A transferência de calor é fortemente dependente da temperatura atingida, cujo cálculo é um elemento importante da modelagem. Foi desenvolvido um algoritmo que permite evitar o cálculo recursivo utilizado para determinação da temperatura de chama, utilizando aproximação por regressões lineares, resultando em redução do tempo computacional e maior convergência.

\subsubsection{Temperatura das pelotas}

O perfil térmico das pelotas é então estimado sequencialmente zona por zona, através do balanço térmico entre entradas e saídas. No algoritmo, entradas e saídas são definidas, calculadas e realimentadas em diferentes pontos, enquanto cálculos recursivos são realizados em busca da minimização do desvio no balanço térmico até obter-se a melhor convergência.

\section{RESULTADOS E DISCUSSÃO}

\subsection{Validação do modelo}

Para validação do modelo, foi realizada amostragem de pelotas das três zonas do forno grelha, a fim de se observar a perda de massa em cada uma delas.

Através do balanço de massa, da energia liberada em cada reação e do aporte térmico fornecido a cada etapa do processo, pôde-se então predizer essa perda através do modelo. Isso garante que caso a reação tenha ocorrido, a temperatura de ativação foi atingida, indicando que a temperatura calculada está correta. 
As Tabelas 4 e 5 apresentam os resultados de PPC (perda por calcinação), umidade e fluxo de massa no leito de pelotas, cujo valor diminui gradativamente ao longo do processamento. A redução no valor da massa se deve ao PPC e umidade.

Tabela 4. Perda de massa de acordo com o modelo proposto

\begin{tabular}{cccccc}
\hline & & Secagem & Pré-queima 1 & Pré-queima 2 & Rotativo \\
\hline PPC & {$[\%]$} & 4,13 & 2,07 & 0,47 & 0 \\
Umidade & {$[\%]$} & 10 & 0 & 0 & 0 \\
Massa & {$[\mathbf{t} / \mathrm{h}]$} & 183,60 & 179,81 & 176,98 & 176,02 \\
\hline
\end{tabular}

Tabela 5. Perda de massa de acordo com análise em laboratório do PPC da pelota

Secagem Pré-queima 1 Pré-queima 2 Rotativo

\begin{tabular}{cccccc}
\hline PPC & {$[\%]$} & 5,30 & 3,75 & 1,30 & 0 \\
Umidade & {$[\%]$} & 10 & 0 & 0 & 0 \\
Massa & {$[\mathrm{t} / \mathrm{h}]$} & 183,60 & 180,75 & 176,25 & 173,86 \\
\hline
\end{tabular}

Comparando os resultados do laboratório com os calculados pelo modelo, pode-se observar que a maior variação de perda de massa ocorreu no forno rotativo, cujo valor foi de $1,24 \%$, desvio considerado irrelevante comparado com a complexidade do processo, conforme demonstrado na Figura 4.

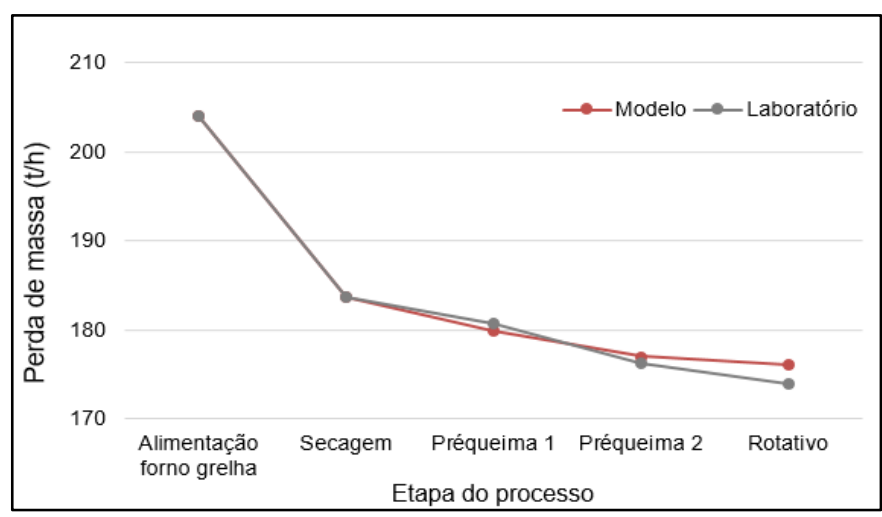

Figura 4. Comparação da perda de massa entre modelo e laboratório

\subsection{Perfil térmico das pelotas}

Conhecer o perfil térmico das pelotas em todas as etapas do processo Grate Kiln é essencial para performance dos fornos. Com o modelamento matemático, essas variáveis são estimadas, garantindo um melhor controle sobre o processo. A Tabela 6 e a Figura 5, abaixo, trazem o perfil térmico do processo calculado com o modelo. O processo de cálculo utiliza dados de termopares da planta em conjunto com dados de perdas térmicas; estimados por radiação através de medições das temperaturas nas paredes externas dos equipamentos do processo. De posse destes dados os balanços térmicos de cada compartimento permitem determinar as temperaturas das 
pelotas. A medição direta destas temperaturas se torna impraticável devido a limitações físicas da planta e limitações de tecnologias disponíveis.

Tabela 6. Perfil térmico da pelota de acordo com o modelo matemático

\begin{tabular}{ccccccc}
\hline Secagem & Pré-queima 1 & Pré-queima 2 & Rotativo & Zona 1 & Zona 2 & Zona 3 \\
\hline $109,9^{\circ} \mathrm{C}$ & $515,1^{\circ} \mathrm{C}$ & $930,5^{\circ} \mathrm{C}$ & $1175,7^{\circ} \mathrm{C}$ & $650,2^{\circ} \mathrm{C}$ & $187,5^{\circ} \mathrm{C}$ & $153,1^{\circ} \mathrm{C}$ \\
\hline
\end{tabular}

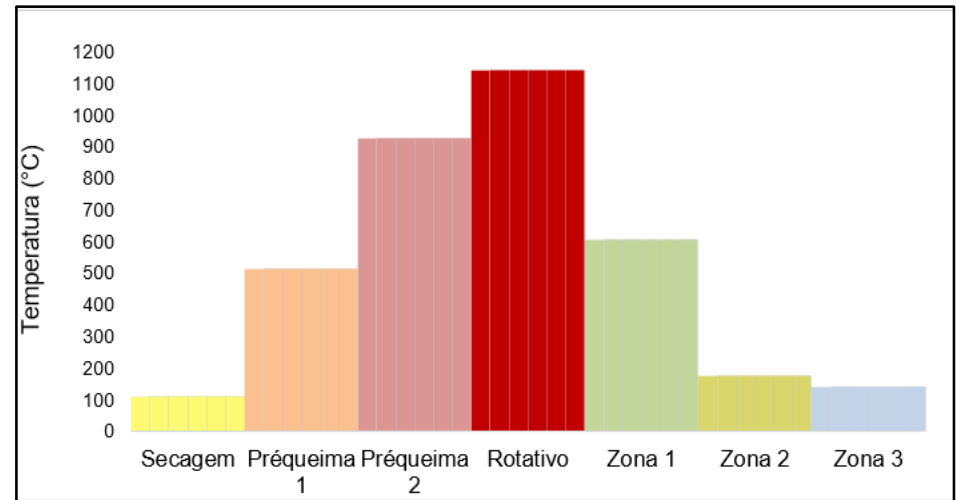

Figura 5. Perfil térmico do processo Grate Kiln.

Estes valores corroboram com as temperaturas de pelota medidas por Wendling [4] através de termopares inseridos no leito de pelotas durante testes de queima simulados em um forno tipo Pot-Grate. A simulação foi feita em escala piloto com matéria prima da VSB e dados de processo, como tempo de processamento e perfil térmico, atualmente utilizados na planta.

\subsection{Simulação de redução de perdas energéticas}

O calor do ar aquecido da zona 2 do resfriador é reaproveitado no aquecimento das pelotas na pré-queima 1. Esse ar é transportado por uma tubulação, onde o ar perde certa quantidade de energia.

$\mathrm{Na}$ situação em estudo, o ar está com $720^{\circ} \mathrm{C}$ na zona 2 e chega na pré-queima 1 a $691^{\circ} \mathrm{C}$, conferindo uma perda de aproximadamente $4 \%$ de energia.

Realizando um processo de simulação com o modelo, pode-se observar através da Figura 6 que há um potencial de economia de 2\% de GN na redução total dessa perda, ou $0,5 \%$ de GN por cada porcentagem de redução.

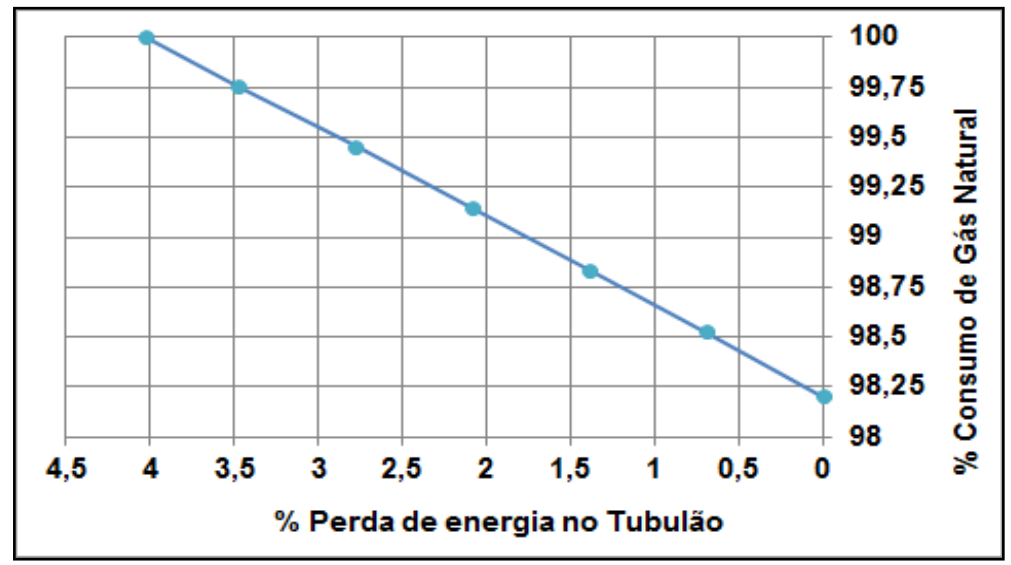

Figura 6. Simulação de redução da perda de calor na tubulação de recuperação da zona 2 (tubulão) 
A tubulação atualmente possui material refratário para minimizar as perdas, porém a aplicação de um material mais eficiente para conter a perda de calor pode gerar redução de perdas significativamente econômicas.

\section{CONCLUSÃO}

O modelo foi desenvolvido e validado para a planta de pelotização da VSB. A validação foi verificada através de duas abordagens, que demonstram a sua eficiência em simular o comportamento mássico e energético da pelota:

- As análises químicas realizadas em cada etapa do forno grelha indicam similaridade com a previsão do modelo;

- O perfil térmico estimado pelo modelo segue tendência conforme a literatura.

Com o modelo validado, a simulação de diversos cenários de operação da planta será de grande valia para geração de ideias para melhorias de processo e reduções dos custos de produção da pelotização. Como exemplo, tivemos:

- A possibilidade de melhoria da recuperação de calor gerado pelo processo mostrou-se uma forma eficiente de economia de combustível no queimador do forno rotativo, de aproximadamente $2 \%$ do consumo total de GN.

\section{REFERÊNCIAS}

1. Juvilar, J. B.; Ratton, A. C. P. Combustão aplicada à Siderurgia. ABM, São Paulo, 1975.

2. Meyer k. Pelletizing of Iron Ores. Spring-Verlog, Berlim Heidelberg, New York, 1980.

3. Carvalho, J. L. R., Assis, P. S., Camilo, R. D., Figueira, R. M., Campos, V. F. Dados termodinâmicos para metalurgistas. Departamento de Engenharia Metalúrgica e de Materiais, Escola de Engenharia, Universidade Federal de Minas Gerais, Belo Horizonte. Revisado em 2008.

4. Wendling, F.; Braga, D. Novo forno piloto para simulação da queima de pelotas de minério de ferro nos processos grelha móvel + forno rotativo. ABM, São Paulo, 2010. 